Front-line reference librarians, behind-thescenes acquisitions librarians, and library administrators alike make distinct contributions to the life of the library. As providers of a key service on campus, librarians of all types are likely be called on at some time to prove themselves. As conscientious librarians, we more often than not also want to measure ourselves to make sure that we are providing the best service possible to our communities.

In "Looking for a few good questions: it really is process, not product" (p. 492), Celia Rabinowitz explores the notion of librarians as guides to learning, rather than managers of information. She suggests that the best gauge of a librarian's success is the degree to which patrons learn to solve their own information needs.

When Steve Bischof and Tim Klassen decided to improve the accessibility of computer manuals at Wesleyan University, they moved them out of the reserves and into a browsable, circulating collection. In "Computer manuals in the academic library collection" on page 506, they use informal circulation statistics to speak to the success of this decision and to help make the argument that these hands-on items deserve to be placed for maximum use.

In "Five years ago ..." (p. 495) Janet Cottrell and Frank Wojcik show us how a straightforward comparison chart, used to measure changes across the library over a five-year period, works as a successful public relations tool for Kenyon College's Library and Information Services. In addition, the chart serves as an information source for everything from faculty advisory committee meetings to "Did you know. . " signs in the library.

Also in this issue is "The library takes the lead" (p. 499), which outlines Wichita State University's leadership role and the process involved in developing a campus-wide Internetuse policy.

-Stephanie Orphan, Editor-in-chief sorphan@ala.org

\title{
University of Maryland University College
}

Center for Intellectual. Property in the Digital Environment

\section{Intellectual Property in Academia Workshop Series}

Asynchronous online workshops of interest to faculty, librarians, distance educators, instructional designers, curriculum specialists, and information professionals:

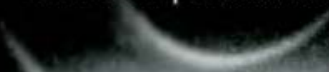

\section{The Shrinking Public Domain}

\author{
September 16-October 4, 2002 \\ Moderated by Laura Gasaway, Esq. \\ Professor of Law, University of North Carolina at Chapel Hill
}

\begin{abstract}
There is considerable concern among academics and copyright scholars that the public domain is being treated as a commodity, thereby resulting in the loss of access to great scholarly, literary, musical, and audiovisual worls. This workshop will explore this complex issue, particularly as it relates to digital information.
\end{abstract}

Participants will receive daily response and feedback from the workshop moderators. Space is limited; please register early! Registration per workshop: $\$ 125$ early; $\$ 150$ regular. Two workshops: $\$ 225$. Three workshops: $\$ 300$. For additional information, call 300-888-UMUC, ext. 7777, or visit our Web page at www.umuc.edu/distance/odell/cip/ipa2002.

Academic Integrity Compliance on College Campuses

October 28-November 15, 2002
Preventing Plagiarism in the Online and Face-to-Face Classroom Spring 2003

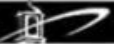

UMUC 